\title{
Proposição de um modelo analítico da tipografia com abordagem semiótica
}

\author{
Proposition of an analytical model of the typography with semiotic approach
}

Daniela Velleda Brisolara

tipografia, design, semiótica, modelo analítico

\begin{abstract}
Este artigo apresenta a estruturação de um modelo analítico da tipografia - resultado de pesquisa de mestrado - fundamentada em sólidas bases teóricas concernentes ao design da informação, tipografia e semiótica. Defende-se, aqui, o caráter fundamentalmente visual do texto (iconicidade da tipografia), passível de 'leitura' antes mesmo do conteúdo verbal. Pretende-se, com este enfoque, atentar para a questão do desenvolvimento de um alfabetismo visual e para o fato de que a configuração (visual e gráfica) da cultura material é produzida tanto pela atuação do design como também pelas contribuições involuntárias de sujeitos não-experts. Acredita-se que tais 'produções tipográficas' tenham muito a dizer sobre o ambiente sóciocultural do qual fazem parte, e que, por isso mesmo, possam fornecer informações importantes à pragmática do design. Deste modo, propõe-se, considerando-se aspectos tipográficos e semióticos, um modelo de análise tipográfica, para ser utilizado em investigações posteriores sobre a tipografia produzida por sujeitos não-experts. O modelo visa descrever semioticamente a tipografia, considerando seus atributos enquanto signo em si, enquanto signo que faz referência a alguma outra coisa e enquanto signo inserido e atuante num determinado contexto. Esta abordagem objetiva apontar os possíveis caminhos pelos quais se dão as escolhas dos sujeitos por uma determinada tipografia (typeface) e por uma determinada estrutura tipográfica.
\end{abstract}

typography, design, semiotics, analytical model

This paper presents the construction of an analytical model of typography - result of master's research based on sound theoretical bases regarding information design, typography and semiotics. The fundamental visual characteristics of a text (typography's iconicity) are defended, which are possible of to be 'read' even before of the verbal content. In this sense, this attends to the question of the visual literacy development and to the fact that the configuration (visual and graphic) of the material culture is produced by design's performance and also by involuntary contribution of non-experts subjects. This study believes that such 'typographic works' have much to inform about the cultural and social environment of which they are constituent of, and thus, these works can provide important information to design's pragmatics. Thus an analytical model of typography is proposed. This model considers the typographic and semiotics features and it can be adopted in later researches about typography produced by non-experts subjects. The model aims to describe the typography semiotically, considering his attributes as a sign itself, as a sign that refers to something else and as a sign inserted and active in a given context. This approach aims to point out the possible choices of subjects for a particular typography (typeface) and a certain typographic structure.

\section{Introdução}

O design gráfico, em termos gerais, pode ser entendido como uma prática comunicativa, intencional e planejada, que articula signos visuais e verbais, tendo como tarefa transmitir uma mensagem, de um emissor para um receptor, visando obter uma determinada produção de sentido (Cauduro, 1998). Essa mensagem é transmitida através de elementos (signos) que representam conceitos, idéias e valores, estabelecidos e interpretados socialmente, ou seja, através de uma determinada linguagem (Santaella, 1999).

O design da informação, por sua vez, como uma área do design gráfico, tem por princípio básico promover melhorias em sistemas de comunicação e informação analógicos e digitais, equacionando os aspectos sintáticos, semânticos e pragmáticos destes sistemas, visando otimizar o processo de aquisição da informação pelo usuário (SBDI, 2006). Para que tal objetivo seja atingido, é necessário que o designer entenda como essa informação será absorvida, que tipo de experiência irá gerar nos usuários e quais os sentidos serão envolvidos na percepção e cognição da informação (Knemeyer, 2003). Ou seja, além de dominar a linguagem (e seus códigos), o designer deve também conhecer e entender o contexto sócio-cultural no qual a informação será processada e no qual está inserido o usuário (sujeito receptor) dessa informação. 
Pode-se, assim, pensar o design - enquanto atividade projetual responsável pela configuração de objetos (artefatos) e transmissão da informação - como uma das fontes mais importantes da cultura material $^{1}$ de uma sociedade (Denis, 1998), conformando um universo de 'interfaces significantes'.

Contudo, juntamente a esse design 'profissional', ou seja, o design produzido por alguém que se especializa em articular as diferentes linguagens (analógicas e digitais, bi e tridimensionais) que tanto transmitem quanto refletem as questões culturais do meio em que se inserem, atuam também os sujeitos não-experts. Estes, em determinadas situações e circunstâncias, onde necessitam resolver problemas e/ou produzir determinada informação visual-gráfica, também se utilizam de signos, pressupostos e convenções para comunicar. A seu modo, tendo algum tipo de noção do que querem atingir (Norman, 1999), e segundo seu repertório e grau de alfabetismo visual, também configuram espaços a serem lidos, agindo como produtores de informação, e não só como usuários-receptores.

O alfabetismo visual, como competência a ser desenvolvida pelo sujeito, pode ser considerado como um processo de ensino e aprendizagem que o habilita a compreender o ambiente circundante e a interpretar e produzir obras da comunicação visual (Debes, 1969).

Porém o desenvolvimento de um alfabetismo 'visual' é quase ignorado no decorrer da formação do indivíduo (Darras, 2004; Dondis, 2000; Fontoura, 2002), visto que a escola ainda enfatiza o modo verbal (lingüístico) em detrimento do visual, limitando a capacidade criadora, crítica e analítica do sujeito.

Partindo-se, então, de um entendimento da tipografia como representação gráfica da língua através de formas específicas que materializam o sistema da escrita e que estruturam um espaço a ser 'lido' (Twyman, 1982; Walker, 2001), este estudo leva em conta o aspecto 'visual' desta leitura. Entende-se, assim, que esta 'representação gráfica' da linguagem verbal é, portanto e fundamentalmente, visual.

Considera-se a estrutura da linguagem desenvolvida por Twyman (1982), segundo a qual a linguagem visual gráfica pode ser verbal, pictórica ou esquemática (Figura 1). O foco de interesse, aqui, dá-se, pois, na linguagem visual gráfica verbal, ou seja, a que se refere à articulação (visualgráfica) do texto. Deste modo, considera-se o caráter visual do signo tipográfico, que tem sido ignorado pela lingüística, psicologia cognitiva e semiologia, sendo abordado por poucos (Leeuwen, 2005).

Figura1: Estrutura da linguagem. Fonte: Adaptado de Twyman (1982, p.7).

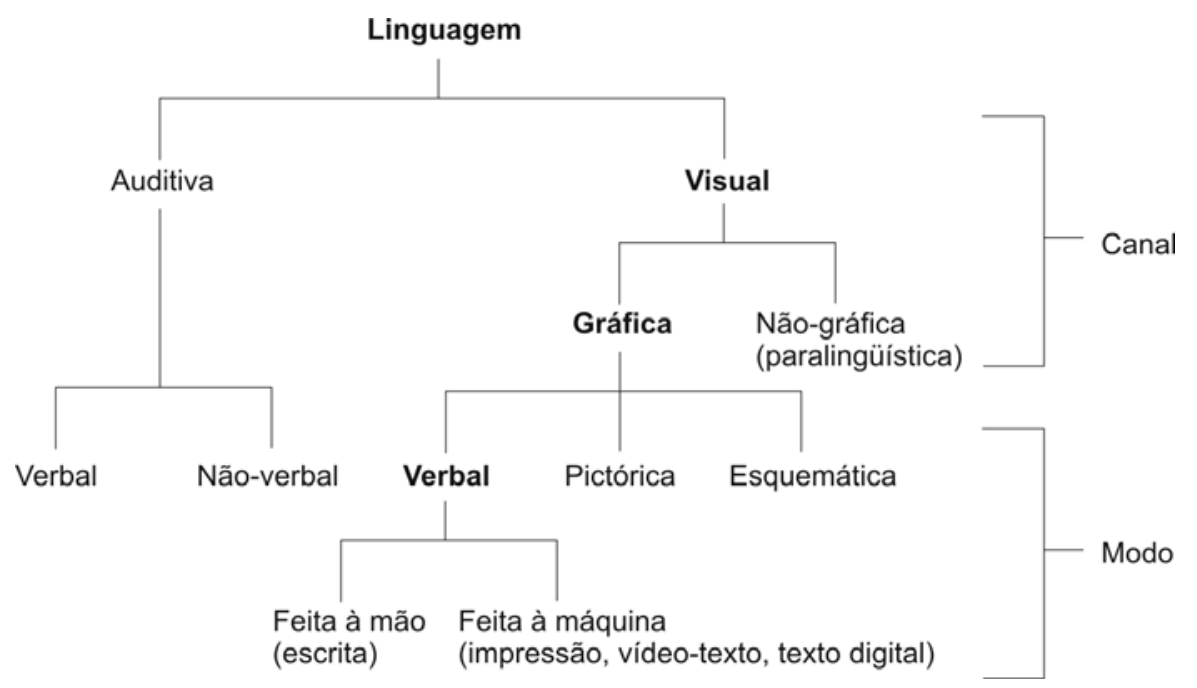

\footnotetext{
${ }^{1}$ Como cultura material entende-se o conjunto de artefatos (objetos feitos pelo homem) produzidos e usados por um determinado grupo ou por uma determinada sociedade, carregados de historicidade, e que transmitem informações sobre o contexto sócio-cultural no qual foi constituído. Quando essa 'cultura material' apresenta-se sob a forma de artefatos gráficos e escritos, pode-se entendê-la como cultura gráfica.
} 
O modo como as linguagens se constituem, por meio de signos e suas relações, produzindo sentido (significando algo pra alguém) e possibilitando a comunicação, é objeto de estudo da Semiótica (Santaella, 1999). A tipografia (linguagem visual gráfica verbal), neste sentido, é um campo extremamente propício para o estudo de 'mudanças semióticas', absorvendo e refletindo marcas de heranças culturais dentro da sociedade que a desenvolve (Leeuwen, 2005; Mandel, 2006). Este estudo toma a tipografia (intrínseca ao design gráfico e informacional) sob esta acepção, como a articulação visual-gráfica da linguagem escrita e sua produção de sentido.

Tal abordagem da tipografia, segundo Walker (2001), não é e (em maior ou menor grau) nunca foi restrita aos experts no assunto (designers / tipógrafos / gráficos), sendo que as pessoas em geral, em seu cotidiano, também articulam graficamente informações textuais para os mais diversos fins. Walker (2001) aponta a importância - tanto social quanto para a formação do conhecimento em design da informação (questões pragmáticas ${ }^{2}$ ) - das investigações sobre regras e convenções seguidas na organização visual da linguagem escrita e destaca a 'tipografia do cotidiano' como uma área fértil para tal investigação.

Avaliar como um sujeito leigo resolve um problema visual-gráfico e o que o leva a fazê-lo de um determinado modo, pode, em muito, contribuir para o conhecimento acerca da linguagem gráfica. Além de que este tipo de investigação parece bastante relevante em tempos onde o desenvolvimento tecnológico propicia um fácil acesso aos meios informatizados de produção e reprodução tipográficas - e quase qualquer pessoa pode produzir seus próprios documentos do começo ao fim (Leeuwen, 2005; Stöckl, 2005; Walker, 2001), contribuindo, mesmo que involuntariamente, para a configuração de um 'panorama tipográfico'.

Sendo o desenvolvimento de um alfabetismo visual uma questão tão negligenciada, conforme aponta a literatura, quais seriam os pressupostos seguidos por esses sujeitos ao estruturarem tipograficamente um espaço?

Tal questão, de acordo com Walker (2001), pode ser respondida através da descrição da organização visual de tipos particulares de manifestação tipográfica, da descrição das regras que as influenciam e da exploração dos fatores contextuais que afetam o que é feito.

Entretanto, os métodos para descrever a tipografia, de um modo geral, recorrem à terminologia dos elementos tipográficos, renomeando-os ou reagrupando-os (Stöckl, 2005), de acordo com as peculiaridades da situação a ser analisada, mas não dão conta, ainda na instância descritiva, dos aspectos semânticos e/ou contextuais.

Uma análise com abordagem semiótica propõe, justamente, considerar os aspectos do signo (tipográfico) em si, mas também a sua relação com outras coisas a que este signo se refere e seu potencial interpretativo considerando um determinado contexto.

Neste intuito, aproximando os universos da tipografia e da semiótica, este artigo apresenta a estruturação de um modelo analítico da tipografia - resultado de pesquisa de mestrado (Brisolara, 2008) -, visando análises posteriores de materiais tipográficos desenvolvidos por não-experts. $O$ modelo toma por base os apontamentos da literatura sobre a 'tipografia do cotidiano', sobre tipografia e modelos utilizados para sua descrição, e sobre os postulados da teoria semiótica peirceana (Charles S. Peirce). O modelo proposto caracteriza-se, então, como o resultado destes cruzamentos teóricos e pretende contribuir como um instrumento metodológico.

\section{Bases para o modelo}

Vários são os parâmetros a serem considerados para uma análise consistente de documentos tipográficos produzidos por sujeitos não-experts. Parâmetros estes que devem dar conta, conforme a proposta aqui apresentada, não somente dos aspectos sintáticos (como na maioria dos modelos encontrados), mas também apontar as prováveis associações semânticas do material, bem como suas características contextuais (tempo/espaço).

\footnotetext{
${ }^{2}$ Em se tratando do design gráfico/design da informação, a 'pragmática' se refere ao estudo do uso e produção de elementos visuais e verbais no contexto comunicacional, considerando seus efeitos na interação social. Nas questões pragmáticas implicam-se, então, aspectos concernentes à cultura, grau de alfabetismo visual e características dos sujeitos/usuários, usabilidade, emoção e processamento da informação (percepção, compreensão, crenças e atitudes, motivação, etc.), dentre outros. O entendimento destes processos permite compreender melhor os sujeitos envolvidos, o meio social e cultural, e, consequentemente, otimizar o design de sistemas de comunicação e informação analógicos e digitais que atuam nestes contextos.
} 
Assim, a partir de conceitos, nomenclaturas e princípios referentes à tipografia, à descrição tipográfica e à prática tipográfica do cotidiano (Bringhurst, 2005; Cauduro, 2002; Farias, 2004; Frascara, 2004; Lupton, 2006; Overmyer, 1991; Schriver, 1997; Stöckl, 2005; Twyman, 1979, 1982; Walker, 2001, dentre outros), e a partir dos preceitos semióticos peirceanos (Coelho Netto, 2001; Farias, 2002; Leeuwen, 2005; Nöth, 1995; Peirce, 2000; Santaella, 1999, 2005; Stöckl, 2005, dentre outros) relacionados ao signo tipográfico, determinou-se quais aspectos deveriam ser considerados e discriminados para a formulação do referido modelo analítico.

\section{Aspectos tipográficos}

Os aspectos tipográficos considerados para a elaboração do modelo analítico baseiam-se nos apontamentos de Walker (2001), nos domínios da tipografia definidos por Stöckl (2005) microtipografia (signos gráficos individuais), mesotipografia (linhas e blocos de texto), macrotipografia (estrutura de todo o documento) e paratipografia (materiais, instrumentos e técnicas de produção) - além da consideração a alguns métodos de descrição tipográfica e nomenclaturas (vários autores) e aos métodos de configuração da linguagem gráfica identificados por Twyman (1979) - linear puro, linear interrompido, lista, linear ramificado, matriz, não linear dirigido e não linear aberto. Partindo-se, então, das categorias (domínios da tipografia) estabelecidas por Stöckl (2005), realizou-se a redefinição das variáveis e considerou-se a inserção dos métodos de configuração da linguagem gráfica (proposta de Twyman, 1979) na categoria da 'macrotipografia', visto que estes se referem às características gerais de um documento. Assim, para descrever a forma como se apresentam e se agrupam os signos tipográficos, ou seja, para a descrição de suas características 'formais', foram definidos os seguintes parâmetros:

1. Microtipografia (design de fontes e signos gráficos individuais)

- Tipo / typeface (Garamond, Helvetica, Arial, Times, etc.);

- Letra feita à mão (manuscritos ou letras desenhadas);

- Tamanho do tipo (pontos);

- Estilo do tipo (traçado, características);

- Cor do tipo (positivo x negativo ou colorido);

- Caixa alta / caixa baixa;

- Capitul ares (ornamentada/colorida);

- Ênfase tipográfica (sublinhado, itálico, negrito, etc.).

2. Mesotipografia (configuração de signos gráficos em linhas e blocos de texto)

- Espaçamento entre letras (padrão, espaçado, reduzido, etc.);

- Espaçamento entre palavras (estreito, largo, etc.);

- Espaçamento entre linhas (espaço duplo/simples);

- Alinhamento (à esquerda, à direita, centralizado, justificado);

- Posição/direção das linhas (horizontal, vertical, diagonal, circular, etc.);

- Recuos e parágrafos (tamanho dos blocos de texto, distância entre blocos).

3. Macrotipografia (estrutura gráfica de todo o documento)

- Dispositivos de organização da informação (titulação hierárquica, numeração, índices, notas, etc.);

- Mancha (tipo)gráfica (quantidade de impressão na página / uso do espaço em branco, margens);

- Mistura de fontes e/ou diferentes modos de produção tipográfica (fontes caligráficas, serifadas, sem serifa, letras feitas à mão, etc.);

- Agrupamento de texto, gráficos e imagens (relação imagem-texto);

- Método de configuração da linguagem gráfica verbal (linear puro, linear interrompido, lista, matriz, etc.). 


\section{Infødesıgn}

4. Paratipografia (materiais, instrumentos e técnicas de reprodução tipográfica)

- Qualidade material do meio (qualidade do papel ou outro suporte, espessura, formato, superfície, etc.);

- Práticas de reprodução (tipo)gráfica (tecnologia utilizada para reprodução do escrito: manual; mecânica; digital; híbrida).

No intuito de tornar o modelo aqui proposto mais abrangente e funcional, algumas variáveis foram acrescentadas e outras foram reposicionadas em relação à estrutura proposta por Stöckl (2005). Assim, na microtipografia foram considerados os diferentes modos de obtenção dos caracteres, ou seja, considerou-se não só a incidência de tipos mecânicos ou digitais, mas também a escrita à mão e/ou letras desenhadas; assim como os aspectos visuais dos tipos (capitulares, ênfases tipográficas) foram considerados como pertencentes à categoria micro. Recuos e parágrafos foram considerados pertencentes ao domínio da mesotipografia, visto que se referem aos blocos de texto. Mancha (tipo)gráfica e mistura de fontes foram considerados como aspectos pertencentes à categoria da macrotipografia, além da inserção do parâmetro 'método de configuração da linguagem gráfica verbal', já mencionado. Finalmente a paratipografia encerra os aspectos referentes à 'reprodução' tipográfica (qualidade do meio e tecnologia empregada para reprodução ou impressão - fotocópia, impressão laser, jato de tinta, etc.), independentemente do modo como o documento foi 'produzido' (se escrito à mão, desenhado ou escrito por métodos mecânicos ou automatizados).

\section{Aspectos semióticos}

O signo tipográfico pode ser tomado como um sistema de significação, operando múltiplas funções que não só a de codificar a linguagem (língua). Sendo assim, a tipografia compreende vários níveis semióticos: além da informação verbal, pode atuar como indicador de valores emocionais, da natureza do documento e da direção de leitura, como também assumir qualidades pictóricas (Stöckl, 2005). Numa correspondência aos três tipos gerais de signos (em relação ao objeto dinâmico), de acordo com a semiótica peirceana - ícone, índice e símbolo - têm-se a essência simbólica do primeiro nível; a indexicalidade do segundo nível e a iconicidade do terceiro.

Deste modo, a partir das considerações sobre uma semiótica da tipografia ${ }^{3}$ e a partir das indicações fornecidas por Walker (2001), estabeleceram-se categorias com as quais o uso/escolha de determinada tipografia e estrutura tipográfica podem estar relacionadas. De acordo com a natureza destas relações, elas podem ser predominantemente: (a) Icônicas - (1) associação imagética; (2) conteúdo do texto (retórica tipográfica); (3) abordagem estética; (b) Indiciais - (4) aparato tecnológico (defaults / experimentações); (5) expressão lingüística (forma oral / forma escrita); ou (c) Simbólicas - (6) noção de autoridade / formalidade / convenções.

1. Associação imagética: quando a escolha por uma determinada tipografia baseia-se na sua semelhança com a aparência de alguma outra coisa.

2. Conteúdo do texto (retórica tipográfica): quando uma determinada estrutura diagramática é utilizada por já ser conhecida e recorrente ("sempre fiz assim"; "aprendi a fazer assim") ou quando é referência para um gênero/estilo específico (como a estruturação em colunas e chamadas para um jornal).

3. Expressão estética e/ou idiossincrática: quando a escolha por uma determinada tipografia se dá por suas características formais em conotação a determinados sentidos (indicando um estilo), ou ainda por questões idiossincráticas (gosto pessoal, humor, estado de espírito).

4. Aparato tecnológico: quando as escolhas por determinada tipografia e/ou estrutura tipográfica é feita, evidentemente, a partir dos meios utilizados (ou pelas limitações deste), como o default do computador, ou experimentações sugeridas/promovidas pelo meio.

5. Expressão lingüística: quando a escolha acompanha unicamente o sentido lingüístico do escrito, reforçando ou acentuando as estruturas sintática, semântica, prosódica e oral do texto verbal (como quando há a repetição de letras para enfatizar a pronúncia ou vários pontos de exclamação para acentuar a expressão).

\footnotetext{
${ }^{3}$ Ver a esse respeito, Brisolara (2008 e/ou 2008a).
} 
6. Autoridade/formalidade/convenções: escolhas baseadas no grau de autoridade e/ou formalidade atribuídas ao documento, determinando o uso de certas convenções e estruturas compositivas.

Entretanto, os signos não dependem somente de 'convenção', de repertório, mas também de que funcionem numa determinada 'situação' (Walther-Bense, 2000). Considerando-se que "(...) as características da linguagem escrita são sempre formadas por variáveis de natureza social, econômica, educacional, legal, religiosa ou tecnológica, numa determinada sociedade, numa determinada língua, num determinado tempo" (Baron, 1998, p.53 apud Walker, 2001, p.10), estabeleceram-se também categorias contextuais nas quais se insere o documento a ser analisado: (1) tipo de documento (gênero); (2) objetivo do trabalho; (3) audiência; (4) circunstâncias de uso; (5) época (ano); (6) localização geográfica e ambiente.

1. Tipo de documento (gênero): definição da natureza do documento produzido (carta, panfleto, jornal, cartaz/anúncio, trabalho escolar, etc.).

2. Objetivo do trabalho: propósito com que o sujeito desenvolveu tal material; intenção da mensagem.

3. Audiência: público a quem o documento se destina.

4. Circunstâncias de uso/veiculação: proporções do material produzido; suporte (fixo/móvel); características peculiares.

5. Época (ano): identificação temporal do material produzido.

6. Localização geográfica e ambiente: identificação local (cidade/país) do documento e ambiente específico em que se dá sua veiculação (ex.: igreja, universidade, ruas, supermercado, escola, etc.).

Dando continuidade à estruturação do modelo, as categorias estabelecidas nos aspectos tipográficos e nos aspectos semióticos foram agrupadas de modo a caracterizar três dimensões distintas para a análise da tipografia: (1) dimensão formal; (2) dimensão sígnica; (3) dimensão contextual.

1. Dimensão formal: dimensão do signo tipográfico em si mesmo, tal como se apresenta em suas características formais e em suas relações estruturais (sintáticas). Compreende os campos da micro, meso, macro e paratipografia.

2. Dimensão sígnica: dimensão que diz respeito ao potencial do signo tipográfico de fazer referência a alguma outra coisa, à qualidades extrínsecas. Estas referências podem ser baseadas em relações icônicas, indiciais e/ou simbólicas. O signo tipográfico é prioritariamente um símbolo e, por isso mesmo, detém características icônicas e indiciais. As categorias discriminadas no modelo pretendem auxiliar na identificação do tipo de relação proeminente, no qual foram baseadas as escolhas por uma determinada tipografia ou estrutura tipográfica.

3. Dimensão contextual: dimensão que situa o signo tipográfico num determinado contexto, discriminando as variáveis que influenciam diretamente sua estruturação.

Assim como os domínios da tipografia (micro, meso, macro e para - dimensão formal) são interdependentes, sobrepondo-se (Stöckl, 2005), também na dimensão sígnica pode ocorrer semelhante situação, onde as escolhas tipográficas são feitas a partir de convenções e normas aprendidas (ground simbólico), mas que eventualmente se caracterizam, prioritariamente, por aspectos icônicos e indiciais. No caso das relações icônicas podem ser identificadas, ainda, características prioritariamente imagéticas (o que o modelo designa como 'associações imagéticas'), diagramáticas (designado como 'conteúdo do texto' no modelo) ou metafóricas (que no modelo apresenta-se como 'expressão estética ou idiossincrática'), sem desconsiderar-se, contudo, o 'encapsulamento' de um nível pelo outro (uma terceiridade que encerra uma secundidade que encerra uma primeiridade, conforme a teoria semiótica).

Sendo assim, o modelo se propõe maleável e adaptável às diversas situações de análise, onde o foco da dimensão sígnica pode estar tanto nas relações icônicas quanto nas indiciais ou simbólicas, ou ainda, pode dar-se simultaneamente, apresentando características que evidenciam os três tipos de relações sígnicas. No caso da dimensão formal, o foco da análise pode estar por vezes na microtipografia, por outras na macrotipografia, por exemplo. Assim, dependendo do tipo de material a ser analisado (volume de texto, tipo de documento, etc.) pode-se suprimir a discriminação referente à microtipografia e focar a descrição nos aspectos da meso ou 


\section{Infodesıgn}

macrotipografia; como também pode haver a situação onde a microtipografia seja a mais relevante e passível de análise, sendo as demais, suprimidas. O modelo comporta-se, deste modo, como um guia descritivo, para o apontamento das características essenciais do material analisado, fazendo referência tanto à configuração formal do documento e sua inserção contextual, como às associações que ele suscita.

A seguir, a estruturação do modelo analítico da tipografia (Tabela 1), levando-se em conta seus aspectos tanto tipográficos quanto semióticos, com vistas ao estudo de materiais produzidos por sujeitos não-experts em design (tipo)gráfico:

Tabela 1 - Modelo analítico e semiótico da tipografia

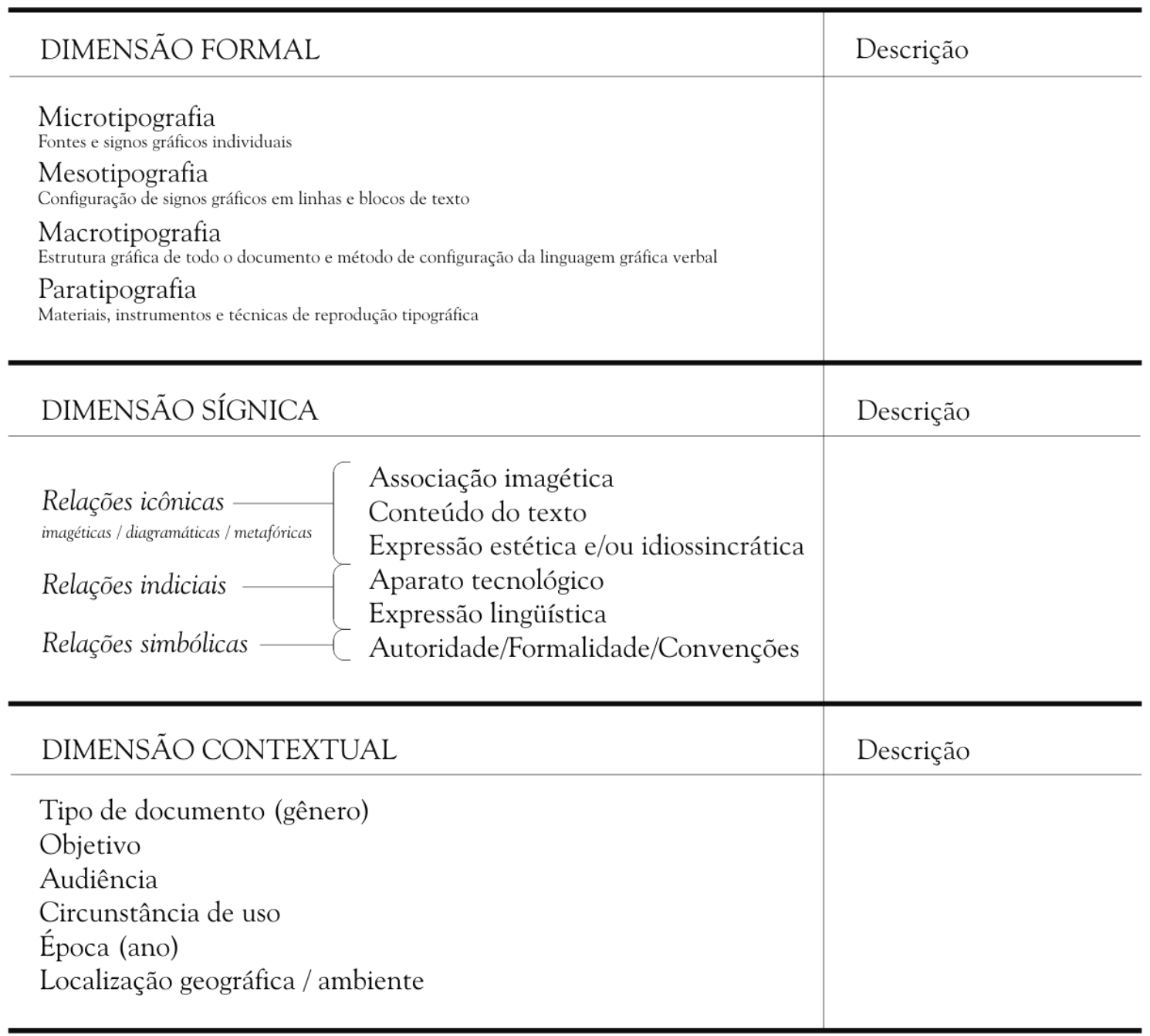

\section{Exemplificação das descrições}

Embora este artigo não se proponha a apresentar resultados de 'aplicação' do modelo analítico formulado, e sim à apresentação do próprio modelo, realizou-se uma 'exemplificação' (Tabela 2) com o intuito de elucidar as descrições. O documento apresentado (Figuras 2) pertence a um contexto escolar e foi escolhido tomando-se por base os argumentos de Walker (2001), segundo os quais o entendimento sobre a organização gráfica da escrita provém, primeiramente, do que foi aprendido na escola. Tal documento - que se trata da capa de um trabalho escolar realizado por estudante da $9^{a}$ série do ensino fundamental - contudo, visa somente exemplificar o uso do modelo analítico aqui proposto. 
Figura 2 - Trabalho escolar (capa), 9a série do ensino fundamental.

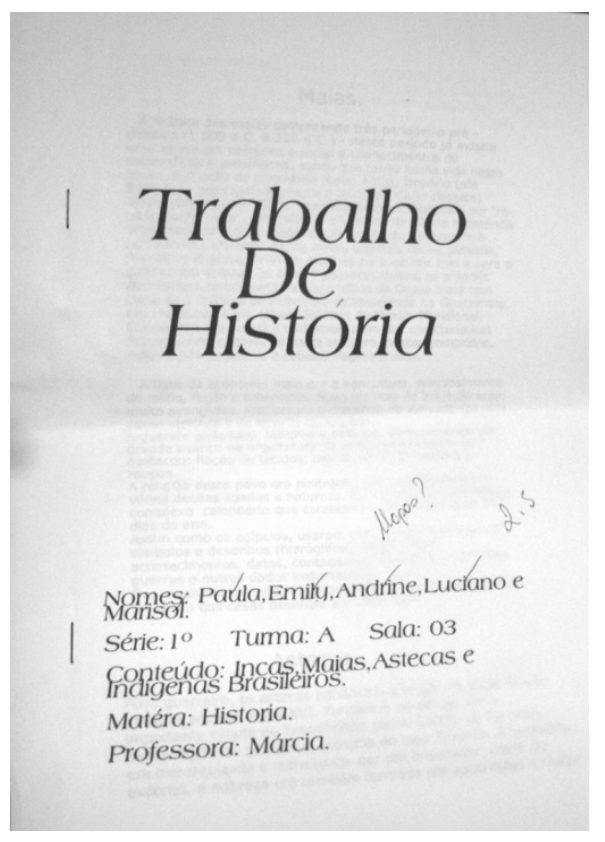

Tabela 2 - Descrição da 'Figura 2' com a utilização do modelo analítico e semiótico da tipografia

\begin{tabular}{|c|c|c|}
\hline DIMENSÃO FORMAL & & Descrição \\
\hline Microtipografia & & $\begin{array}{l}\text { Tipografia semi-serifada (incisas); impressão positiva; } \\
\text { caixa alta e baixa; ênfase tipográfica dada por } \\
\text { diferenciação no tamanho do tipo }\end{array}$ \\
\hline Mesotipografia & & $\begin{array}{l}\text { Espaçamento padrão, entre letras e entre palavras; } \\
\text { espaçamento negativo entre linhas; alinhamento } \\
\text { centralizado e alinhado à esquerda; posição horizontal das } \\
\text { linhas de texto; blocos de texto de tamanhos diferentes }\end{array}$ \\
\hline Macrotipografia & & $\begin{array}{l}\text { Titulação hierárquica; utilização do espaço em branco; } \\
\text { utilização de apenas uma fonte; método de configuração } \\
\text { não linear dirigido }\end{array}$ \\
\hline Paratipografia & & $\begin{array}{l}\text { Tecnologia digital (impressão em jato de tinta); } \\
\text { documento impresso em papel, formato A4 }\end{array}$ \\
\hline DIMENSÃO SÍGNICA & & Descrição \\
\hline $\begin{array}{l}\text { Relações icônicas } \\
\text { imagéticas / diagramáticas / metafóricas }\end{array}$ & $\begin{array}{l}\text { Associação imagética } \\
\text { Conteúdo do texto } \\
\text { Expressão estética e/ou } \\
\text { idiossincrática }\end{array}$ & $\begin{array}{l}\text { Estrutura corriqueira em trabalhos escolares } \\
\text { Julgamento de adequação da fonte ao conteúdo do } \\
\text { texto (conteúdo histórico - trabalho sobre os Maias) }\end{array}$ \\
\hline Relações indiciais & $\begin{array}{l}\text { Aparato tecnológico } \\
\text { Expressão lingüística }\end{array}$ & \\
\hline Relações simbólicas & $\begin{array}{l}\text { Autoridade/Formalidade/ } \\
\text { Convenções }\end{array}$ & Conteúdo formal (trabalho escolar de História) \\
\hline
\end{tabular}

(continua) 


\begin{tabular}{l|l}
\hline DIMENSÃO CONTEXTUAL & Descrição \\
\hline Tipo de documento (gênero) & Trabalho escolar \\
\hline Objetivo & $\begin{array}{l}\text { Atender a uma determinada disciplina escolar } \\
\text { (capa de trabalho escolar) }\end{array}$ \\
\hline Audiência & Professor da disciplina \\
\hline Circunstância de uso & Material para ser lido em mãos \\
\hline Época (ano) & 2007 \\
\hline Localização geográfica / ambiente & $\begin{array}{l}\text { Pelotas/RS/Brasil/ contexto escolar } \\
\text { (ambiente de sala de aula) }\end{array}$ \\
\hline
\end{tabular}

\section{Considerações sobre o modelo e sua aplicabilidade}

A utilização do modelo analítico fornece informações (descritivas) sobre a seleção tipográfica do documento e sobre sua estrutura e método de configuração (ambos na dimensão formal), e sobre os possíveis fatores que influenciaram estas escolhas (sígnicos e contextuais).

Walker (2001, p.29) alerta, contudo, que

um dos problemas em se conduzir análises de documentos produzidos por designers não-experts é que, em face do material, não sabemos exatamente como um documento particular foi verdadeiramente projetado, ou como as decisões foram verdadeiramente feitas, e [sendo assim], temos que inferir estas informações a partir da evidência gráfica que nos é apresentada. Isto ajuda a situar uma mensagem ou documento particular dentro de um contexto social e, ainda que a descrição do uso de determinadas convenções espaciais e gráficas possam ser interpretativas [subjetivas], ela é um reconhecimento importante do fato que o design (seja feito por um expert ou por um não-expert) é um processo influenciado e afetado por diversos fatores.

E ainda Santaella (2005, p.43), a respeito de análises semióticas, afirma não haver "nenhum critério apriorístico que possa infalivelmente decidir como uma dada semiose funciona, pois tudo depende do contexto de sua atualização e do aspecto pelo qual é observada e analisada". Porém, mesmo não havendo receitas, ressalta que há conceitos e uma lógica para a possível aplicação da análise, que deve ser respeitada.

Deve-se ressaltar que o modelo proposto caracteriza-se enquanto instrumento de análise a ser utilizado em contextos específicos por pesquisas de cunho etnográfico e compreensivo, onde deve atuar como uma operação metodológica da fase das descrições que, aliada a outras operações, pode servir de base à fase interpretativa. Num primeiro momento a leitura feita pelo pesquisador, tendo por base a evidência gráfica (o material produzido) - tal como indica Walker (2001) - situa o documento contextualmente e infere as possíveis razões que impulsionaram a escolha por uma determinada tipografia e/ou estrutura tipográfica. Por isso mesmo, recomenda-se que a análise seja complementada por outras fontes de informação, tal como uma entrevista com quem produziu o documento tipográfico, ou, preferencialmente, através da observação do sujeito produzindo este material. Deste modo o pesquisador poderá confirmar suas inferências e realizar descrições e interpretações mais coerentes com o fato empírico, sem, contudo, abdicar de seus paradigmas metodológicos.

O modelo analítico e semiótico da tipografia, aqui apresentado, se propõe, então, a realizar um 'diagnóstico' sobre o material tipográfico analisado, porém, deve-se salientar que ele atua como um mecanismo de auxílio ao estudo e compreensão do signo tipográfico e sua estruturação espacial, e não de modo hermético ou absoluto.

\section{Conclusão}

Entender o design como área do conhecimento e prática profissional inserida num determinado meio cultural, cujo panorama (material, gráfico, visual) ajuda a formar e do qual é reflexo, é afirmar sua veia social, antes de qualquer outra. Justamente por isso não pode prescindir do 
conhecimento oriundo de outras áreas e de abordagens diversas, pois sua atuação depende de fatores relativos ao sujeito (conhecer, por exemplo, seus processos cognitivos) e ao contexto (ambientes situacionais, meio sócio-cultural).

Esses sujeitos (público-alvo, usuário, receptor da informação, dentre outras designações) também são, assim como o design (e os 'designers profissionais'), reflexo e refletores da cultura onde se inserem. $E$, além da fruição, leitura e uso do meio que os cercam, também a produção de artefatos e de informação emerge em suas práticas cotidianas. Tal produção - que também faz parte do contingente material da cultura -, no entanto, é vagamente declarada e investigada.

Em se tratando da produção de linguagem gráfica, uma série de questões (tributárias do design) vem à tona, como o entendimento de uma determinada articulação de signos, pressupostos e convenções seguidas, o papel da tecnologia, das 'regras instituídas', enfim, dos hábitos que envolvem tal produção.

Já no início dos anos 80, Twyman (1982) apontava para o fato de que a articulação da linguagem gráfica começava a se transferir do especialista para o leigo. Segundo Twyman (1982, p.19), "estamos nos aproximando de uma situação tal que qualquer pessoa alfabetizada terá quase tanto controle sobre o que é apresentado graficamente como sobre aquilo que é falado". Por isso mesmo, segundo ele, "mais do que nunca é necessário estudarmos a linguagem gráfica, e particularmente a linguagem gráfica verbal" (Twyman, 1982, p.18).

A partir de tais constatações Twyman (1982, p.20-21) atenta para o impacto das tecnologias e o que ele chama de 'traduzibilidade gráfica do texto' (sua flexibilidade, transformação e 'adequação' de um sistema para outro). Aponta também para a necessidade de uma educação visual e gráfica, o que remete à questão do desenvolvimento de um alfabetismo visual - ponto recorrente e defendido por diversos autores.

Deve-se ressaltar, contudo, que tal desenvolvimento não faz do sujeito um 'designer', no sentido 'profissional' do termo, mas o habilita a dominar determinados códigos elementares, e, consequentemente, a comunicar-se de forma mais adequada, além de tornar-se um receptor/usuário (e também um possível 'cliente') mais consciente e familiarizado com o universo do design e sua importância.

Conforme aponta Walker (2001, p.15), "as pessoas crescem com uma consciência voluntária ou involuntária sobre a história da linguagem gráfica e o que é culturalmente apropriado. Poucos escapam da influência da palavra impressa na forma de livros, jornais, etc. (...) e da crescente influência da palavra digital, como o e-mail e a web". A partir daí, das diversas linguagens (tipo)gráficas com as quais entram em contato diariamente, as pessoas formam seu repertório, seu entendimento, sua identificação com tais estruturas e formas. E a partir daí as disseminam.

Sendo assim, investigar como um sujeito leigo resolve um problema visual-gráfico - no caso aqui, particularmente tipográfico - e o que o leva a fazê-lo de um determinado modo, possibilita delinear o tipo de relação estabelecida entre este sujeito e a linguagem visual gráfica verbal (tipografia). Em outras palavras, este tipo de investigação promove um meio de entender o raciocínio do sujeito, suas escolhas, sua cultura. Questões imprescindíveis à pragmática do design.

Nesse sentido, o modelo aqui proposto apresenta-se como uma ferramenta metodológica para a análise da tipografia produzida por sujeitos não-experts em design (tipo)gráfico. O modelo se propõe a investigar variações possíveis na linguagem tipográfica, como, por exemplo, em relação a diferentes tecnologias (o que inclui transposições e adaptações de estruturas tipográficas de sistemas analógicos para sistemas digitais) ou diferentes épocas e culturas; além de investigar questões concernentes ao sujeito e seus processos cognitivos. Com isso, intenta contribuir diretamente com o campo do design (gráfico e informacional) e tipografia.

\section{Agradecimento}

Agradeço à CAPES pelo apoio a minha pesquisa de Mestrado através da bolsa de estudos.

\section{Referências}

Bringhurst, Robert. 2005. Elementos do estilo tipográfico. São Paulo: Cosacnaify.

Brisolara, Daniela Velleda. 2008. Design (tipo)gráfico e Semiótica: proposição de um modelo 


\section{Infodesıgn}

analítico e semiótico da tipografia produzida por não-experts. Curitiba, 2008. 156p. Dissertação (Mestrado em Design) - Programa de Pós-Graduação em Design, Universidade Federal do Paraná - UFPR.

Brisolara, Daniela Velleda. 2008a. Princípios para a proposição de um modelo analítico da tipografia com abordagem semiótica. Anais do $8^{\circ}$ Congresso Brasileiro de Pesquisa e Desenvolvimento em Design - P\&D Design 2008, São Paulo.

Cauduro, Flávio Vinícius. 1998. A prática semiótica do design gráfico. Verso\&Reverso, n. 27, pp.63-84.

Cauduro, Flávio Vinícius. 2002. Design tipográfico e subjetividade. Anais do $5^{\circ}$ Congresso Brasileiro de Pesquisa e Desenvolvimento em Design - P\&D Design 2002, São Paulo.

Coelho Netto, J. Teixeira. 2001. Semiótica, informação e comunicação. Coleção Debates. São Paulo: Perspectiva.

Darras, Bernard. 2004. Children's drawing and information design education. A semiotic and cognitive approach of visual literacy. Selected Readings of the Information Design International Conference 2003. In: Carla Galvão Spinillo e Solange Coutinho (Eds.). Recife: Sociedade Brasileira de Design da Informação, pp.105-118.

Debes, John. 1969. The Loom of Visual Literacy. Audiovisual Instruction, v.14, n.8, pp.25-27.

Denis, Rafael Cardoso. 1998. Design, cultura material e o fetichismo dos objetos. Revista Arcos. Design, cultura material e visualidade, v.1, número único, Rio de Janeiro, pp.14-39.

Farias, Priscila Lena. 2002. Sign Design, ou o design dos signos: a construção de diagramas dinâmicos das classes de signos de C.S.Peirce. São Paulo, 2002. 214p. Tese (Doutorado em Comunicação e Semiótica) - Programa de Estudos Pós-Graduados em Comunicação e Semiótica Pontifícia Universidade Católica de São Paulo.

Farias, Priscila Lena. 2004. Notas para uma normatização da nomenclatura tipográfica. Anais do $6^{\circ}$ Congresso Brasileiro de Pesquisa e Desenvolvimento em Design - P\&D Design 2004, São Paulo.

Frascara, Jorge. 2004. Communication design: principles, methods, and practice. New York: Allworth Press.

Fontoura, A. M. 2002. EdaDe - educação de crianças e jovens através do design. Florianópolis, 2002. 337p. Tese (Doutorado em Engenharia da Produção) - Programa de Pós-Graduação em Engenharia de Produção, UFSC.

Knemeyer, N. 2003. Information Design: The Understanding Discipline. In: <http://www.boxesandarrows.com/archives> 05/12/2006.

Leeuwen, Theo van. 2005. Typographic meaning. Visual Comunication, v.4, n.2, pp.138-143.

Mandel, Ladislas. 2006. Escritas, espelho dos homens e das sociedades. São Paulo: Ed. Rosari.

Norman, Donald A. 1999. The design of everyday things. London: The MIT Press.

Nöth, Winfried. 1995. Panorama da Semiótica: de Platão a Peirce. São Paulo: Annablume.

Overmyer, D. 1991. On situating documents: notes toward a descriptive and analytical framework. Information Design Journal, v.6, n.3, p.199-209.

Peirce, Charles S. 2000. Semiótica. São Paulo: Perspectiva.

Santaella, Lúcia. 1999. O que é Semiótica. São Paulo: Brasiliense.

Santaella, Lúcia. 2005. Semiótica Aplicada. São Paulo: Thomson.

Schriver, Karen. 1997. Dinamics in document design. New York: John Wiley \& Sons.

Stöckl, Hartmut. 2005. Typography: body and dress of a text - a signing mode between language and image. Visual Comunication, v. 4, n.2, pp.204-214.

Twyman, Michael. 1979. A schema for the study of graphic language. Kolers, P.A., Wrolstad, M.E. \& Bouma, H. (Eds.). Processing of visible language. New York \& London: Plenum Press, v.1, pp.117-150.

Twyman, Michael. 1982. The graphic presentation of language. Information Design Journal. John 
Benjamins Publishing Co., v.3, n.1, pp.2-22.

Walker, Sue. 2001. Typography and language in everyday life. Prescriptions and Practices. London: Pearson Education.

Walther-Bense, Elisabeth. 2000. A Teoria Geral dos Signos. São Paulo: Perspectiva.

\section{Sobre a autora}

Daniela Velleda Brisolara é Bacharel em Design gráfico (2002) pela Universidade Federal de Pelotas (UFPel) e Mestre em Design (2008) pela Universidade Federal do Paraná (UFPR). É docente nos cursos de Design (comunicação visual e design de móveis) do Instituto Federal Sul Rio-Grandense e suas principais áreas de atuação são design da informação e semiótica, com enfoque em tipografia.

<danibrisolara@pelotas.ifsul.edu.br>

<danidesign@msn.com> 